\title{
Erector spinae plane block for postoperative analgesia in pediatric oncological thoracic surgery
}

\author{
Felipe Muñoz, MD · Javier Cubillos, MD • Antonio J. Bonilla, MD • \\ Ki Jinn Chin, MBBS, MMED, FRCPC (1)
}

Received: 23 February 2017/Revised: 18 April 2017/Accepted: 21 April 2017 /Published online: 26 April 2017

(C) Canadian Anesthesiologists' Society 2017

\section{To the Editor,}

The erector spinae plane (ESP) block is a novel technique in which local anesthetic (LA) is deposited in the fascial plane deep to the erector spinae muscle and superficial to the tip of the transverse process. It achieves extensive multi-dermatomal sensory block of the posterior, lateral, and anterior thoracic wall. ${ }^{1}$ Its analgesic effect appears due to LA diffusion into the paravertebral space, affecting both the dorsal and ventral rami of the thoracic spinal nerves, ${ }^{1}$ as well as the rami communicantes which supply the sympathetic chain. ${ }^{2}$ After having obtained parental informed consent, we performed the ESP block as part of successful perioperative pain management in a pediatric patient undergoing oncological thoracic surgery.

A seven-year-old boy was scheduled for resection of a large $(5 \times 5 \times 4 \mathrm{~cm})$ tumor of the 11 th right rib (Figure A). A single-shot ultrasound-guided ESP block was planned for postoperative analgesia - but only to be performed following completion of the surgery to avoid possible disruption of the surgical planes. Anesthesia was induced with sevoflurane and, prior to the incision, intravenous fentanyl $3.0 \mu \mathrm{g} \cdot \mathrm{kg}^{-1}$, diclofenac $0.3 \mu \mathrm{mg} \cdot \mathrm{kg}^{-1}$, and dexamethasone $4.0 \mathrm{mg}$ were administered. The operation lasted four hours, during which time the right 11th rib and associated tumour were removed through a posterolateral incision.

F. Muñoz, MD · J. Cubillos, MD · A. J. Bonilla, MD Department of Anesthesia, Javeriana University School of Medicine, Bogotá, Colombia

K. J. Chin, MBBS, MMED, FRCPC ( $\square)$

Department of Anesthesia, University of Toronto, Toronto, ON, Canada

e-mail: gasgenie@gmail.com
Prior to emergence and with the patient still in a lateral position, an ESP block was performed at the level of the T8 transverse process (the most caudal level accessible without disrupting the wound dressing) using a 10- to 15 $\mathrm{MHz}$ linear-array transducer placed in a parasagittal plane $2 \mathrm{~cm}$ from the posterior midline. A $22 \mathrm{G} 50-\mathrm{mm}$ block needle was inserted in-plane in a craniocaudal direction to contact the tip of the T8 transverse process (Figure B and C). Correct needle tip location was confirmed by injecting $0.5-1 \mathrm{~mL}$ of bupivacaine $0.5 \%$ with epinephrine $5 \mu \mathrm{g} \cdot \mathrm{mL}^{-1}$ and visualizing the linear LA spread (i.e., hydrodissection) in the fascial plane between the erector spinae muscle and the transverse process. A total of $14 \mathrm{~mL}$ of LA was injected that was seen on ultrasonography to spread from the T5 transverse process to at least T11. The wound dressing precluded further assessment of the caudal limit of spread.

Following extubation and transfer to the post-anesthetic care unit (PACU), the patient was noted to have a COMFORT Behavior scale score of 11 [scores range from 6 (no pain) to 30 (greatest pain)], consistent with mild pain. ${ }^{3}$ Systemic multimodal analgesia was initiated prior to PACU discharge with intravenous tramadol $2 \mathrm{mg} \cdot \mathrm{kg}^{-1}$ and oral acetaminophen $15 \mathrm{mg} \cdot \mathrm{kg}^{-1}$. Analgesia was continued with intravenous metamizole $20 \mathrm{mg} \cdot \mathrm{kg}^{-1}$ (a common nonopioid analgesic in Latin America but unavailable in Canada) ${ }^{4}$ every six hours and oral acetaminophen 15 $\mathrm{mg} \cdot \mathrm{kg}^{-1}$ every eight hours.

Pain was assessed every four hours using the WongBaker FACES ${ }^{5}$ and COMFORT Behavior pain rating scale. The patient continued to report only mild pain at the surgical site up to $32 \mathrm{hr}$ after surgery, when he complained of moderate pain, which was successfully treated with two doses of intravenous morphine $100 \mu \mathrm{g} \cdot \mathrm{kg}^{-1}$. No further opioid was required before hospital discharge on the third 


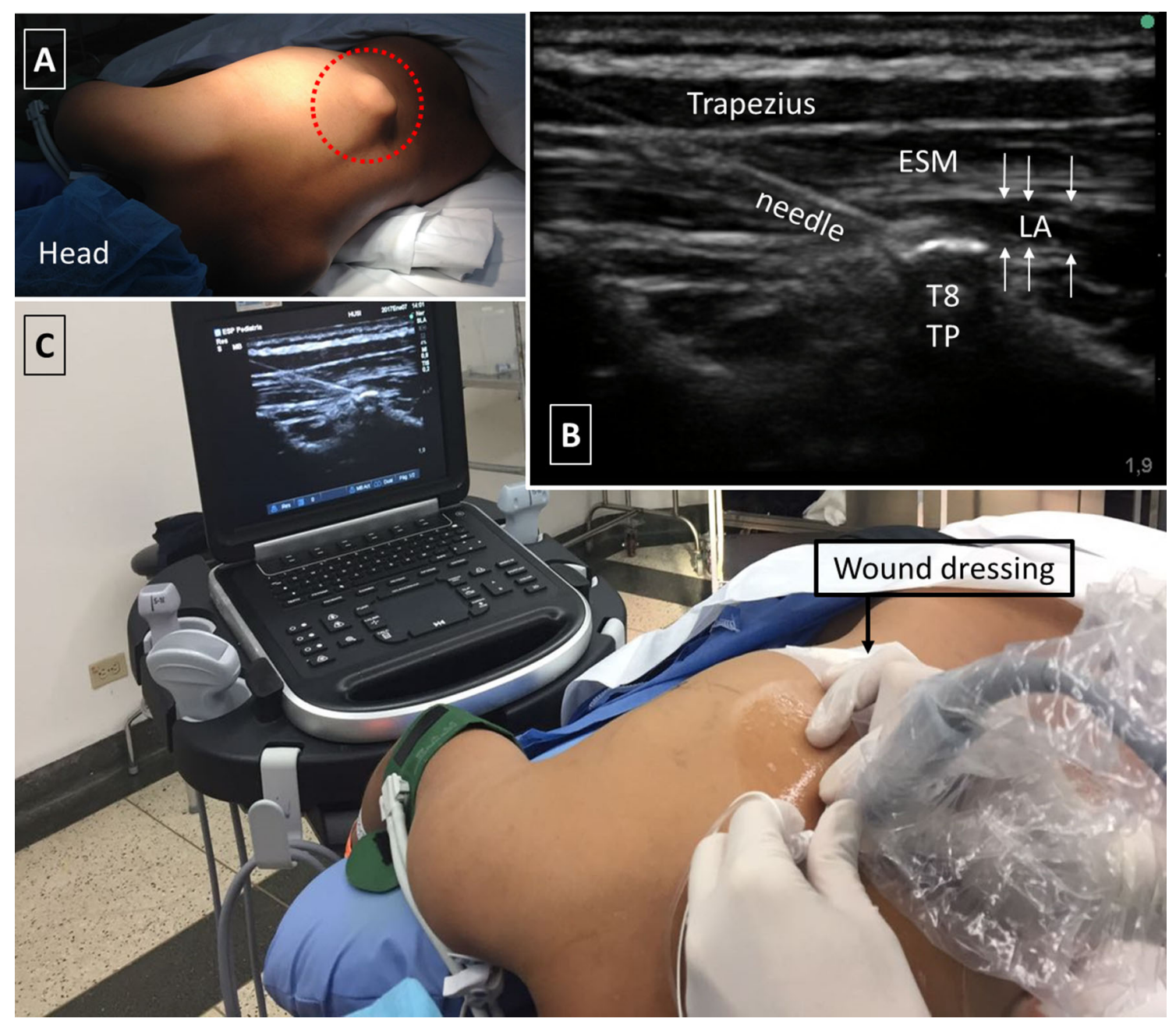

Figure (A) Tumour arising from the posterior right 11th rib. (B) and (C) Ultrasound-guided erector spinae plane block performed at the end of surgery at the level of the T8 transverse process (TP) and superior to the surgical wound and dressing. The needle is inserted inplane through the erector spinae muscle (ESM) to contact the

postoperative day with oral acetaminophen every eight hours as his only analgesic.

The analgesic benefits of regional anesthesia for pediatric thoracic surgery must be carefully weighed against the potential risks, particularly as these blocks are generally performed in the anesthetized patient. The ESP block holds promise as a simpler, safer alternative to thoracic epidural or paravertebral block because the sonographic target is easily visualized, and the site of injection is distant from the neuraxis, pleura, and major vascular structures. In addition, the fascial plane underlying the erector spinae muscle permits extensive craniocaudal spread - and thus multi-dermatomal coverage - with a single injection. ${ }^{1}$ It allowed us to perform the ESP block at a distance from the surgical site and still achieve wound analgesia. Further studies are warranted to validate these observations. transverse process. Injection in the correct plane results in extensive linear spread of local anesthetic (LA, arrows) in a craniocaudal direction that separates the ESM from the transverse processes

Ethics approval Exempted from approval.

\section{Conflict of interest None declared.}

Editorial responsibility This submission was handled by Dr. Hilary P. Grocott, Editor-in-Chief, Canadian Journal of Anesthesia.

Funding No specific funding related to this study. Dr. Ki Jinn Chin is supported by a Merit Award from the Department of Anesthesia, University of Toronto.

\section{References}

1. Forero M, Adhikary SD, Lopez H, Tsui C, Chin KJ. The erector spinae plane block: a novel analgesic technique in thoracic neuropathic pain. Reg Anesth Pain Med 2016; 41: 621-7. 
2. Chin KJ, Malhas L, Perlas A. The erector spinae plane block provides visceral abdominal analgesia in bariatric surgery: a report of three cases. Reg Anesth Pain Med 2017; 42: 372-6.

3. van Dijk M, Peters JW, van Deventer P, Tibboel D. The COMFORT Behavior Scale: a tool for assessing pain and sedation in infants. Am J Nurs 2005; 105: 33-6.
4. Kotter $T$, da Costa BR, Fassler M, et al. Metamizole-associated adverse events: a systematic review and meta-analysis. PLoS One 2015; 10: e0122918.

5. Wong DL, Baker CM. Pain in children: comparison of assessment scales. Pediatr Nurs 1988; 14: 9-17. 